DOI: https://doi.org/10.33330/jurteksi.v5i1.294

Available online at http://jurnal.stmikroyal.ac.id/index.php/jurteksi

\title{
SISTEM PENDUKUNG KEPUTUSAN PENERIMAAN PEGAWAI DI STMIK ROYAL METODE SIMPLE ADDITIVE WEIGHTING
}

\author{
Afrisawati \\ Program Studi Sistem Informasi, STMIK Royal Kisaran \\ Jl. Prof. M. Yamin 173 Kisaran, Sumatera Utara 21222, Telp : (0623) 41079 \\ E-mail : afrisawaty@gmail.com
}

\begin{abstract}
Abstrack: New Employee Recruitment on campus STMIK ROYAL. In the selection usually the campus will provide several series of tests to determine the ability and personal of the prospective employee. Data test results will be stored in an archive or computer in the form of tables that create data and value of each test participant. Based on the current employee recruitment system HR has difficulty in selecting and evaluating the competent employees. To overcome this made a decision support system of new employee acceptance especially part of laboratory assistant. For determine employees who will be accepted, then built a computerized decision-making system that is able to facilitate the process of receiving new employees. the determination and identification of labor by using SAW method (Simple additive weighting) is a method that can find a best alternative from various alternatives based on predetermined criteria. The point is that the method determines the weight value for each criterion. The best alternatives are those who are eligible to be employees based on predetermined criteria. Assessment is done by finding the value of weight for each criterion, then conducted the ranking process that will determine the optimal alternative that is the employee who will be considered by the decision maker to become employees at the company. This decision support system will be able to assist the human resources in determining the recruitment of new employees, especially the assistant laboratory at STMIK ROYAL.
\end{abstract}

Keywords: assessment criteria, SAW method, decision support system.

Abstrak: Penerimaan Karyawan baru pada kampus STMIK ROYAL. Dalam penyeleksian
biasanya pihak kampus akan memberikan beberapa rangkaian tes untuk mengetahui
kemampuan serta pribadi dari calon pegawai tersebut. Data hasil tes tersebut nantinya akan
disimpan dalam suatu arsip ataupun komputer yang berupa tabel yang membuat data dan nilai
masing-masing peserta tes. Berdasarkan system penerimaan pegawai yang berjalan saat ini
SDM mengalami kesulitan dalam menyeleksi dan mengevaluasi pegawai yang berkompeten.
Untuk mengatasinya dibuat suatu sistem pendukung keputusan penerimaan pegawai baru
khususnya bagian asisten laboraturium.Untuk menentukan pegawai yang akan diterima, maka
dibangun sebuah sistem pengambilan keputusan terkomputerisasi yang mampu memudahkan
proses penerimaan pegawai baru. penentuan dan identifikasi tenaga kerja dengan
menggunakan metode SAW (Simple additive weighting) adalah metode yang dapat mencari
suatu alternatif terbaik dari berbagai alternatif berdasarkan kriteria - kriteria yang telah
ditentukan. Intinya bahwa metode tersebut menentukan nilai bobot pada setiap kriteria.
Alternatif terbaik yang dimaksud adalah yang berhak menjadi pegawai berdasarkan kriteria
yang telah ditentukan. Penilaian dilakukan dengan mencari nilai bobot untuk setiap kriteria,
kemudian dilakukan proses perangkingan yang akan menentukan alternatif optimal yaitu para 
DOI: https://doi.org/10.33330/jurteksi.v5i1.294

Available online at http://jurnal.stmikroyal.ac.id/index.php/jurteksi

pegawai yang akan dipertimbangkan oleh pengambil keputusan untuk menjadi pegawai pada perusahaan tersebut. Sistem pendukung keputusan ini nantinya dapat mambantu pihak SDM dalam menentukan perekrutan karyawan baru khususnya asisten laboraturium di STMIK ROYAL.

Kata Kunci : kriteria penilaian, metode SAW, sistem pendukung keputusan.

\section{PENDAHULUAN}

Salah satu faktor pendukung perkembangan kampus adalah sumber daya manusia yang berkualitas, sehingga menjadi hal yang penting dalam penyeleksian calon pegawai secara tepat, sehingga menghasilkan pegawai yang sesuai dengan kebutuhan kampus. Seringkali dalam Penerimaan pegawai baru menjadi hal yang sulit karena harus sesuai dengan criteria yang dibutuhkan kampus.

Dalam penyeleksian biasanya pihak kampus akan memberikan beberapa rangkaian tes untuk menegetahui kemampuan serta pribadi dari calon pegawai tersebut. Data hasil tes tersebut nantinya akan disimpan dalam suatu arsip ataupun komputer yang berupa tabel yang membuat data dan nilai masing-masing peserta tes. Berdasarkan system penerimaan pegawai yang berjalan saat ini SDM mengalami kesulitan dalam menyeleksi dan mengevaluasi pegawai yang berkompeten. Untuk mengatasinya diperlukan aplikasi system pendukung keputusan yang akan membantu bagian SDM dalam proses penyeleksian pegawaiuntuk menentukan pegawai mana yang diterima.

Untuk menentukan pegawai yang akan diterima, maka dibangun sebuah sistem pengambilan keputusan terkomputerisasi yang mampu memudahkan proses penerimaan pegawai baru. penentuan dan identifikasi tenaga kerja dengan menggunakan metode SAW (Simple additive weighting) adalah metode yang dapat mencari suatu alternatif terbaik dari berbagai alternatif berdasarkan kriteria - kriteria yang telah ditentukan. Intinya bahwa metode tersebut menentukan nilai bobot pada setiap kriteria. Alternatif terbaik yang dimaksud adalah yang berhak menjadi pegawai berdasarkan kriteria yang telah ditentukan. Penilaian dilakukan dengan mencari nilai bobot untuk setiap kriteria, kemudian dilakukan proses perangkingan yang akan menentukan alternatif optimal yaitu para pegawai yang akan dipertimbangkan oleh pengambil keputusan untuk menjadi pegawai pada perusahaan tersebut.

Alasan memilih metode $S A W$ karena metode ini memiliki keunggulan. Diantaranya adalah mudah dimengerti, lebih fleksibel, dapat memecahkan persoalan yang kompleks dan melakukan pembelajaran berdasarkan pengetahuan dan pengalaman manusia dalam memecahkan suatu masalah. Berdasarkan latar belakang diatas maka salah satu bentuk upaya dalam pelaksanaanya diperlukan suatu Sistem Pendukung Keputusan Penerimaan Pegawai di STMIK ROYAL menggunakan Metode SAW.

Sesuai dengan latar belakang 
DOI: https://doi.org/10.33330/jurteksi.v5i1.294

Available online at http://jurnal.stmikroyal.ac.id/index.php/jurteksi

masalah di atas maka dijabarkan beberapa rumusan masalah yaitu: Bagaimana merancang sistem pendukung keputusan penerimaan pegawai di STMIK ROYAL .Bagaimana menerapkan metode SAW dalam penerimaan pegawai di STMIK ROYAL yang diaplikasikan berbasis web.

Ruang lingkup pembahasan dalam penelitian ini adalah mengangkat pembahasan mengenai sistem penerimaan pegawai di STMIK ROYAL Kisaran. Khususnya pegawai asisten laboraturium. Sistem pendukung keputusan yang akan dibangun menggunakan metode Simple Additive [Weighting, sistem ini dirancang menggunakan bahasa pemrograman $P H P \& M Y S Q L$.

\section{Sistem Pendukung Keputusan}

Sistem Pendukung Keputusan (SPK) atau dikenal dengan Decision Support System (DSS), pada tahun 1970-an sebagai pengganti istilah Management Information System (MIS). Pada dasarnya sistem pendukung keputusan merupakan pengembangan lebih lanjut dari MIS yang dirancang sedemikian rupa sehingga bersifat interaktif dengan pemakainya. Maksud dan tujuan dari SPK, yaitu untuk mendukung pengambil keputusan memilih alternatif keputusan yang merupakan hasil pengolahan informasi-informasi yang diperoleh/tersedia dengan menggunakan model-model pengambil keputusan serta untuk menyelesaikan masalah-masalah bersifat terstruktur, semi terstruktur dan tidak terstruktur [1].
Komponen-komponen tersebut membentuk sistem aplikasi sistem pendukung keputusan yang bisa dikoneksikan ke intranet perusahaan, esktranet, atau internet. Arsitektur dari sistem pendukung keputusan ditunjukkan pada gambar berikut [2]:

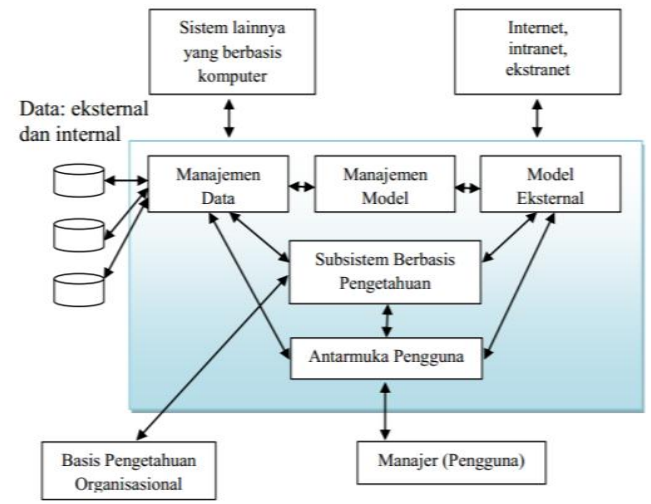

Gambar 1 Arsitektur Sistem Pendukung Keputusan

\section{Metode Simple Additive Weighting}

Metode SAW merupakan metode MADM yang paling sederhana dan paling banyak digunakan. Metode ini juga metode yang paling mudah untuk diaplikasikan, karena mempunyai algoritma yang tidak terlalu rumit. Metode SAW sering juga dikenal sebagai metode penjumlahan terbobot [3]. Konsep dasar metode SAW adalah mencari penjumlahan terbobot dari rating kinerja pada setiap alternatif pada semua atribut. Metode SAW membutuhkan proses normalisasi matriks keputusan (X) ke suatu skala yang dapat diperbandingkan dengan semua rating alternatif yang ada [3].

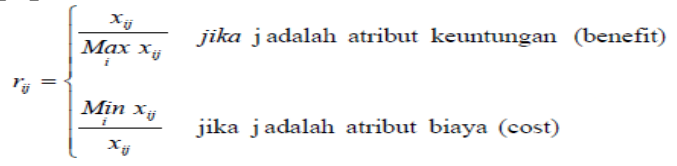


DOI: https://doi.org/10.33330/jurteksi.v5i1.294

Available online at http://jurnal.stmikroyal.ac.id/index.php/jurteksi

Dimana

Rij : Rating kinerja ternormalisasi

Maximum: Nilai maksimum dari setiap baris dan kolom

Minimum: Nilai minimum dari setiap baris dan kolom

Xij: Baris dan kolom dari matriks

Dimana rij adalah rating kinerja ternormalisasi dari alternatif $\mathrm{Ai}$ pada atribut $\mathrm{Cj} ; \mathrm{i}=1,2, \ldots, \mathrm{m}$ dan $\mathrm{j}=1,2, \ldots, \mathrm{n}$. Nilai preferensi untuk setiap alternative (Vi) diberikan sebagai:

$$
V_{i}=\sum_{j=1}^{n} w_{j} r_{i j}
$$

Gambar 3: Formula untuk mencari nilai preverensi

Vi : Nilai Akhir Alternative

Wi : Bobot yang telah ditentukan

Rij : Normalisasi matriks

Nilai Vi yang lebih besar mengindikasikan bahwa alternatif ai lebih terpilih.

\section{METODE}

\section{Observasi}

Mengidentifikasi dan menganalisis masalah Analisis masalah pada penelitian ini dilakukan dengan dua metode yaitu metode deskriptif.

Metode Deskriptif. Pada metode ini data yang ada dikumpulkan, disusun, dikelompokkan dan dianalisis sehingga diperoleh beberapa gambaran yang jelas pada masalah yang akan dibahas.

Pengumpulan Data

Adapun metode pengumpulan data yang dilakukan oleh penulis adalah sebagai berikut:

a. Observasi

Yaitu metode pengumpulan data melalui pendekatan ke lapangan dengan mengambil data-data yang ada di lapangan atau melakukan peninjauan secara langsung ke objek yang diteliti dan dapat dilakukan dengan cara:

b. wawancara (Interview),

penulis melakukan wawancara (take and give) kepada bapak kepala dinas beserta staf-nya untuk memperoleh keterangan-keterangan yang lebih komplit.

c. Dokumen

Penulis mengumpulkan berupa dokumen-dokumen yang diperlukan dari tempat-tempat riset terkait yang digunakan untuk keperluan penelitian.

d. Kuesioner

Penulis memberikan kuesiner kepada staf-staf yang ada pada instansi terkait.

\section{HASIL DAN PEMBAHASAN}

\section{Hasil}

\section{Pemberian Bobot Per Kriteria}

langkah awal metode Simple Additive Weighting adalah pemberian nilai bobot di setiap kriteria penerimaan karyawan. Ada 5 kreteria dalam penelitian ini, dapat dilihat pada tabel berikut:

Tabel.1 Pemberian bobot Perkreteria

\begin{tabular}{lll}
\hline & Keterangan & Bobot \\
\hline C1 & $\begin{array}{l}\text { Seleksi Berkas/ } \\
\text { Jurusan/Pendidikan Terakhir }\end{array}$ & 0.6 \\
\hline C2 & Bekerjasama Tim & 0.8 \\
\hline C3 & $\begin{array}{l}\text { Kemampuan Merakit } \\
\text { Komputer }\end{array}$ & 0.8 \\
\hline C4 & $\begin{array}{l}\text { Kemampuan Instalasi } \\
\text { Komputer }\end{array}$ & 1 \\
\hline C5 & $\begin{array}{l}\text { Kemampuan Instalasi } \\
\text { Jaringan }\end{array}$ & 0.8 \\
\hline C6 & Wawancara & 0.4 \\
\hline
\end{tabular}


DOI: https://doi.org/10.33330/jurteksi.v5i1.294

Available online at http://jurnal.stmikroyal.ac.id/index.php/jurteksi

Tabel. 2 untuk criteria 1 (C1)

\begin{tabular}{lll}
\hline $\begin{array}{l}\text { Seleksi } \\
\text { Berkas }\end{array}$ & Nilai & Keterangan \\
\hline 1 & 0,2 & Jurusan MI/D3 \\
\hline 2 & 0,4 & $\begin{array}{l}\text { Jurusan MI/D3/Sertifikat } \\
\text { Keahlian }\end{array}$ \\
\hline 3 & 0,6 & Jurusan TK/D3 \\
\hline 4 & 0,8 & $\begin{array}{l}\text { Jurusan TK/D3/Sertifikat } \\
\text { Keahlian }\end{array}$ \\
\hline 5 & 1 & Jurusan SK/S1 \\
\hline
\end{tabular}

Tabel. 3 untuk criteria 2 (C2)

\begin{tabular}{lll}
\hline $\begin{array}{l}\text { Bekerjasama } \\
\text { Tim }\end{array}$ & Nilai & Keterangan \\
\hline 1 & 0,2 & Sangat buruk \\
\hline 2 & 0,4 & Buruk \\
\hline 3 & 0,6 & Cukup \\
\hline 4 & 0,8 & Baik \\
\hline 5 & 1 & Sangat Baik \\
\hline
\end{tabular}

Tabel. 4 untuk criteria 3 (C3) Kemampuan Nilai Keterangan merakit

\section{Komputer}

\begin{tabular}{lll}
\hline 1 & 0,2 & Sangat buruk \\
\hline 2 & 0,4 & Buruk \\
\hline 3 & 0,6 & Cukup \\
\hline 4 & 0,8 & Baik \\
\hline 5 & 1 & Sangat Baik \\
\hline
\end{tabular}

Tabel. 5 untuk criteria 4 (c4)

\begin{tabular}{lll}
\hline $\begin{array}{l}\text { Kemampuan } \\
\text { instalasi } \\
\text { komputer }\end{array}$ & Nilai & Keterangan \\
\hline 1 & 0,2 & Sangat buruk \\
\hline 2 & 0,4 & Buruk \\
\hline 3 & 0,6 & Cukup \\
\hline 4 & 0,8 & Baik \\
\hline 5 & 1 & Sangat Baik \\
\hline
\end{tabular}

Tabel. 6 untuk criteria 5 (C5)

\begin{tabular}{lll}
$\begin{array}{l}\text { Kemampuan } \\
\text { instalasi } \\
\text { jaringan }\end{array}$ & Nilai & Keterangan \\
\hline 1 & 0,2 & Sangat buruk \\
\hline 2 & 0,4 & Buruk \\
\hline 3 & 0,6 & Cukup \\
\hline 4 & 0,8 & Baik \\
\hline 5 & 1 & Sangat Baik \\
\hline
\end{tabular}

Tabel 7 untuk criteria 6 (C6)

\begin{tabular}{lll}
\hline Wawancara & Nilai & Keterangan \\
\hline 1 & 0,2 & Sangat buruk \\
\hline 2 & 0,4 & Buruk \\
\hline 3 & 0,6 & Cukup \\
\hline 4 & 0,8 & Baik \\
\hline 5 & 1 & Sangat Baik \\
\hline
\end{tabular}

Tabel. 8 data hasil Penilaian

\begin{tabular}{lcccccc}
\hline \multirow{2}{*}{ Alternatif } & \multicolumn{7}{c}{ Kriteria } \\
\cline { 2 - 7 } & C1 & C2 & C3 & C4 & C5 & C6 \\
\hline Fauzi Ahmad & 0.4 & 0.4 & 0.4 & 0.6 & 0.8 & 0.6 \\
\hline Sahren & 0.6 & 0.4 & 0.8 & 0.6 & 0.8 & 0.6 \\
\hline Ricky & 0.2 & 0.4 & 0.8 & 0.6 & 0.8 & 0.4 \\
\hline Rudy Hermawan & 0.2 & 0.4 & 0.4 & 0.4 & 0.4 & 0.2 \\
\hline Riko & 0.4 & 0.4 & 0.2 & 0.2 & 0.4 & 0.2 \\
\hline Ridwan & 0.2 & 0.4 & 0.8 & 0.4 & 0.6 & 0.4 \\
\hline Hendra Kurniawan & 0.4 & 0.4 & 0.2 & 0.2 & 0.2 & 0.4 \\
\hline Junaidi & 0.6 & 0.4 & 0.8 & 0.2 & 0.6 & 0.4 \\
\hline Widra Widhana & 0.4 & 0.4 & 0.8 & 0.4 & 0.6 & 0.4 \\
\hline
\end{tabular}


JURTEKSI (Jurnal Teknologi dan Sistem Informasi)

Vol. V No. 1, Des 2018, hlm. 53 - 60

DOI: https://doi.org/10.33330/jurteksi.v5i1.294

Available online at http://jurnal.stmikroyal.ac.id/index.php/jurteksi

Matriks keputusan dibuat dari tabel kecocokan sebagai berikut:

$$
X=\left\{\begin{array}{l}
0.4,0.4,0.4,0.6,0.8,0.6 \\
0.6,0.4,0.8,0.6,0.8,0.6 \\
0.2,0.4,0.8,0.6,0.8,0.4 \\
0.2,0.4,0.4,0.4,0.4,0.2 \\
0.4,0.4,0.2,0.2,0.4,0.2 \\
0.2,0.4,0.8,0.4,0.6,0.4 \\
0.4,0.4,0.2,0.2,0.2,0.4 \\
0.6,0.4,0.8,0.2,0.6,0.4 \\
0.4,0.4,0.8,0.4,0.6,0.4
\end{array}\right\}
$$

Normalisasi matrik

\section{a. Kriteria Seleksi \\ berkas/Jurusan/Pendidikan \\ Terakhir}

R11 :

$x=\frac{0.4}{\operatorname{Max}\{0.4 ; 0.6 ; 0.2 ; 0.2 ; 0.4 ; 0.2 ; 0.4 ; 0.6 ; 0.4\}}=\frac{0.4}{0.6}=0.67$

R21 :

$x=\frac{0.6}{\operatorname{Max}\{0.4 ; 0.6 ; 0.2 ; 0.2 ; 0.4 ; 0.2 ; 0.4 ; 0.6 ; 0.4\}}=\frac{0.6}{0.6}=1$

R31 :

$x=\frac{0.2}{\operatorname{Max}\{0.4 ; 0.6 ; 0.2 ; 0.2 ; 0.4 ; 0.2 ; 0.4 ; 0.6 ; 0.4\}}=\frac{0.2}{0.6}=0.33$

R41 :

$x=\frac{0.2}{\operatorname{Max}\{0.4 ; 0.6 ; 0.2 ; 0.2 ; 0.4 ; 0.2 ; 0.4 ; 0.6 ; 0.4\}}=\frac{0.2}{0.6}=0.33$

R51 :

$x=\frac{0.4}{\operatorname{Max}\{0.4 ; 0.6 ; 0.2 ; 0.2 ; 0.4 ; 0.2 ; 0.4 ; 0.6 ; 0.4]}=\frac{0.4}{0.6}=0.67$

R61 :

$x=\frac{0.2}{\operatorname{Max}\{0.4 ; 0.6 ; 0.2 ; 0.2 ; 0.4 ; 0.2 ; 0.4 ; 0.6 ; 0.4\}}=\frac{0.2}{0.6}=0.33$

R71 :

$x=\frac{0.4}{\operatorname{Max}\{0.4 ; 0.6 ; 0.2 ; 0.2 ; 0.4 ; 0.2 ; 0.4 ; 0.6 ; 0.4\}}=\frac{0.4}{0.6}=0.67$

R81 :

$x=\frac{0.6}{\operatorname{Max}\{0.4 ; 0.6 ; 0.2 ; 0.2 ; 0.4 ; 0.2 ; 0.4 ; 0.6 ; 0.4\}}=\frac{0.6}{0.6}=1$

R91 :

$x=\frac{0.4}{\operatorname{Max}\{0.4 ; 0.6 ; 0.2 ; 0.2 ; 0.4 ; 0.2 ; 0.4 ; 0.6 ; 0.4\}}=\frac{0.4}{0.6}=0.67$

\section{b. Kriteria bekerjasama tim}

$\mathrm{R} 21$

$x=\frac{0.4}{\max \{(0.4 ; 0.8 ; 0.8 ; 0.4 ; 0.2 ; 0.8 ; 0.2 ; 0.8 ; 0.8\}}=\frac{0.4}{0.8}=0.5$

R22
ISSN 2407-1811 (Print)

ISSN 2550-0201 (Online) $x=\frac{0.8}{\max \{0.4 ; 0.8 ; 0.8 ; 0.4 ; 0.2 ; 0.8 ; 0.2 ; 0.8 ; 0.8\}}=\frac{0.8}{0.8}=1$

R23

$x=\frac{0.8}{\max \{0.4 ; 0.8 ; 0.8 ; 0.4 ; 0.2 ; 0.8 ; 0.2 ; 0.8 ; 0.8\}}=\frac{0.8}{0.8}=1$

R24

$x=\frac{0.4}{\max \{0.4 ; 0.8 ; 0.8 ; 0.4 ; 0.2 ; 0.8 ; 0.2 ; 0.8 ; 0.8\}}=\frac{0.4}{0.8}=0.5$

$\mathrm{R} 25$

$x=\frac{0.2}{\max \{0.4 ; 0.8 ; 0.8 ; 0.4 ; 0.2 ; 0.8 ; 0.2 ; 0.8 ; 0.8\}}=\frac{0.2}{0.8}=0.25$

R26

$x=\frac{0.8}{\max \{0.4 ; 0.8 ; 0.8 ; 0.4 ; 0.2 ; 0.8 ; 0.2 ; 0.8 ; 0.8\}}=\frac{0.8}{0.8}=1$

$\mathrm{R} 27$

$x=\frac{0.2}{\max \{0.4 ; 0.8 ; 0.8 ; 0.4 ; 0.2 ; 0.8 ; 0.2 ; 0.8 ; 0.8\}}=\frac{0.2}{0.8}=0.25$

R28

$x=\frac{0.8}{\max \{0.4 ; 0.8 ; 0.8 ; 0.4 ; 0.2 ; 0.8 ; 0.2 ; 0.8 ; 0.8\}}=\frac{0.8}{0.8}=1$

R29

$x=\frac{0.8}{\max \{0.4 ; 0.8 ; 0.8 ; 0.4 ; 0.2 ; 0.8 ; 0.2 ; 0.8 ; 0.8\}}=\frac{0.8}{0.8}=1$

\section{c. Kriteria Kemampuan merakit komputer}

$\mathrm{R} 31$

$x=\frac{0.6}{\max \{0.6 ; 0.6 ; 0.6 ; 0.4 ; 0.2 ; 0.4 ; 0.2 ; 0.2 ; 0.4\}}=\frac{0.6}{0.6}=1$

R32

$x=\frac{0.6}{\max \{0.6 ; 0.6 ; 0.6 ; 0.4 ; 0.2 ; 0.4 ; 0.2 ; 0.2 ; 0.4\}}=\frac{0.6}{0.6}=1$

R33

$x=\frac{0.6}{\max \{0.6 ; 0.6 ; 0.6 ; 0.4 ; 0.2 ; 0.4 ; 0.2 ; 0.2 ; 0.4\}}=\frac{0.6}{0.6}=1$

R34

$x=\frac{0.4}{\max \{0.6 ; 0.6 ; 0.6 ; 0.4 ; 0.2 ; 0.4 ; 0.2 ; 0.2 ; 0.4\}}=\frac{0.4}{0.6}=0.67$

R35

$x=\frac{0.2}{\max \{0.6 ; 0.6 ; 0.6 ; 0.4 ; 0.2 ; 0.4 ; 0.2 ; 0.2 ; 0.4\}}=\frac{0.2}{0.6}=0.33$

R36

$x=\frac{0.4}{\max \{0.6 ; 0.6 ; 0.6 ; 0.4 ; 0.2 ; 0.4 ; 0.2 ; 0.2 ; 0.4\}}=\frac{0.4}{0.6}=0.67$

R37

$x=\frac{0.2}{\max \{0.6 ; 0.6 ; 0.6 ; 0.4 ; 0.2 ; 0.4 ; 0.2 ; 0.2 ; 0.4\}}=\frac{0.2}{0.6}=0.33$

$\mathrm{R} 38$

$x=\frac{0.2}{\max \{0.6 ; 0.6 ; 0.6 ; 0.4 ; 0.2 ; 0.4 ; 0.2 ; 0.2 ; 0.4\}}=\frac{0.2}{0.6}=0.33$

R39 
JURTEKSI (Jurnal Teknologi dan Sistem Informasi)

Vol. V No. 1, Des 2018, hlm. 53 - 60

DOI: https://doi.org/10.33330/jurteksi.v5i1.294

Available online at http://jurnal.stmikroyal.ac.id/index.php/jurteksi $x=\frac{0.4}{\max \{0.6 ; 0.6 ; 0.6 ; 0.4 ; 0.2 ; 0.4 ; 0.2 ; 0.2 ; 0.4\}}=\frac{0.4}{0.6}=0.67$

Kriteria Kemampuan instalasi

komputer

R41

$x=\frac{0.8}{\max \{0.8 ; 0.8 ; 0.8 ; 0.4 ; 0.4 ; 0.6 ; 0.2 ; 0.6 ; 0.6\}}=\frac{0.8}{0.8}=1$

$\mathrm{R} 42$

$x=\frac{0.8}{\max \{0.8 ; 0.8 ; 0.8 ; 0.4 ; 0.4 ; 0.6 ; 0.2 ; 0.6 ; 0.6\}}=\frac{0.8}{0.8}=1$

$\mathrm{R} 43$

$x=\frac{0.8}{\max \{0.8 ; 0.8 ; 0.8 ; 0.4 ; 0.4 ; 0.6 ; 0.2 ; 0.6 ; 0.6\}}=\frac{0.8}{0.8}=1$

R44

$x=\frac{0.4}{\max \{0.8 ; 0.8 ; 0.8 ; 0.4 ; 0.4 ; 0.6 ; 0.2 ; 0.6 ; 0.6\}}=\frac{0.4}{0.8}=0.5$

$\mathrm{R} 45$

$x=\frac{0.4}{\max \{0.8 ; 0.8 ; 0.8 ; 0.4 ; 0.4 ; 0.6 ; 0.2 ; 0.6 ; 0.6\}}=\frac{0.4}{0.8}=0.5$

$\mathrm{R} 46$

$x=\frac{0.6}{\max \{0.8 ; 0.8 ; 0.8 ; 0.4 ; 0.4 ; 0.6 ; 0.2 ; 0.6 ; 0.6\}}=\frac{0.6}{0.8}=0.75$

R47

$x=\frac{0.2}{\max \{0.8 ; 0.8 ; 0.8 ; 0.4 ; 0.4 ; 0.6 ; 0.2 ; 0.6 ; 0.6\}}=\frac{0.2}{0.8}=0.25$

$\mathrm{R} 48$

$x=\frac{0.6}{\max \{0.8 ; 0.8 ; 0.8 ; 0.4 ; 0.4 ; 0.6 ; 0.2 ; 0.6 ; 0.6\}}=\frac{0.6}{0.6}=1$

$\mathrm{R} 49$

$x=\frac{0.6}{\max \{0.8 ; 0.8 ; 0.8 ; 0.4 ; 0.4 ; 0.6 ; 0.2 ; 0.6 ; 0.6\}}=\frac{0.6}{0.6}=1$

\section{d. Kriteria Kemampuan Instalasi Jaringan}

R51

$x=\frac{0.6}{\max \{0.6 ; 0.6 ; 0.4 ; 0.2 ; 0.2 ; 0.4 ; 0.4 ; 0.4 ; 0.4\}}=\frac{0.6}{0.6}=1$

$\mathrm{R} 52$

$x=\frac{0.6}{\max \{0.6 ; 0.6 ; 0.4 ; 0.2 ; 0.2 ; 0.4 ; 0.4 ; 0.4 ; 0.4\}}=\frac{0.6}{0.6}=1$

R53

$x=\frac{0.4}{\max \{0.6 ; 0.6 ; 0.4 ; 0.2 ; 0.2 ; 0.4 ; 0.4 ; 0.4 ; 0.4\}}=\frac{0.4}{0.6}=0.67$

R54

$x=\frac{0.2}{\max \{0.6 ; 0.6 ; 0.4 ; 0.2 ; 0.2 ; 0.4 ; 0.4 ; 0.4 ; 0.4\}}=\frac{0.2}{0.6}=0.33$

R55

$x=\frac{0.2}{\max \{0.6 ; 0.6 ; 0.4 ; 0.2 ; 0.2 ; 0.4 ; 0.4 ; 0.4 ; 0.4\}}=\frac{0.2}{0.6}=0.33$

R56
ISSN 2407-1811 (Print)

ISSN 2550-0201 (Online)

$x=\frac{0.4}{\max \{0.6 ; 0.6 ; 0.4 ; 0.2 ; 0.2 ; 0.4 ; 0.4 ; 0.4 ; 0.4\}}=\frac{0.4}{0.6}=0.67$

R57

$x=\frac{0.4}{\max \{0.6 ; 0.6 ; 0.4 ; 0.2 ; 0.2 ; 0.4 ; 0.4 ; 0.4 ; 0.4\}}=\frac{0.4}{0.6}=0.67$

R58

$x=\frac{0.4}{\max \{0.6 ; 0.6 ; 0.4 ; 0.2 ; 0.2 ; 0.4 ; 0.4 ; 0.4 ; 0.4\}}=\frac{0.4}{0.6}=0.67$

R59

$x=\frac{0.4}{\max \{0.6 ; 0.6 ; 0.4 ; 0.2 ; 0.2 ; 0.4 ; 0.4 ; 0.4 ; 0.4\}}=\frac{0.4}{0.6}=0.67$

\section{e. Kriteria Wawancara}

R61

$x=\frac{0.6}{\max \{0.6 ; 0.6 ; 0.2 ; 0.2 ; 0.4 ; 0.2 ; 0.2 ; 0.6 ; 0.4\}}=\frac{0.6}{0.6}=1$

R62

$x=\frac{0.6}{\max \{0.6 ; 0.6 ; 0.2 ; 0.2 ; 0.4 ; 0.2 ; 0.2 ; 0.6 ; 0.4\}}=\frac{0.6}{0.6}=1$

R63

$x=\frac{0.2}{\max \{0.6 ; 0.6 ; 0.2 ; 0.2 ; 0.4 ; 0.2 ; 0.2 ; 0.6 ; 0.4\}}=\frac{0.2}{0.6}=0.33$

R64

$x=\frac{0.2}{\max \{0.6 ; 0.6 ; 0.2 ; 0.2 ; 0.4 ; 0.2 ; 0.2 ; 0.6 ; 0.4\}}=\frac{0.2}{0.6}=0.33$

R65

$x=\frac{0.4}{\max \{0.6 ; 0.6 ; 0.2 ; 0.2 ; 0.4 ; 0.2 ; 0.2 ; 0.6 ; 0.4\}}=\frac{0.4}{0.6}=0.67$

R66

$x=\frac{0.2}{\max \{0.6 ; 0.6 ; 0.2 ; 0.2 ; 0.4 ; 0.2 ; 0.2 ; 0.6 ; 0.4\}}=\frac{0.2}{0.6}=0.33$

R67

$x=\frac{0.2}{\max \{0.6 ; 0.6 ; 0.2 ; 0.2 ; 0.4 ; 0.2 ; 0.2 ; 0.6 ; 0.4\}}=\frac{0.2}{0.6}=0.33$

R68

$x=\frac{0.6}{\max \{0.6 ; 0.6 ; 0.2 ; 0.2 ; 0.4 ; 0.2 ; 0.2 ; 0.6 ; 0.4\}}=\frac{0.6}{0.6}=1$

R69

$x=\frac{0.4}{\max \{0.6 ; 0.6 ; 0.2 ; 0.2 ; 0.4 ; 0.2 ; 0.2 ; 0.6 ; 0.4\}}=\frac{0.4}{0.6}=0.67$

$\mathrm{X}=\left\{\begin{array}{c}0.67,0.5,1,1,1,1 \\ 1,1,1,1,1,1 \\ 0.33,1,1,1,0.67,0.33 \\ 0.33,0.5,0.67,0.5,0.33,0.33 \\ 0.67,0.25,0.33,0.5,0.33,0.67 \\ 0.33,1,0.67,0.75,0.67,0.33 \\ 0.67,0.25,0.33,0.25,0.67,0.33 \\ 1,1,0.33,1,0.67,1 \\ 0.67,1,0.67,1,0.67,0.67\end{array}\right\}$

Melakukan proses perangkingan dengan

bobot variabel $(\mathrm{W})=\{0,6 ; 0,8 ; 0,8 ; 1 ; 0,4\}$ 
DOI: https://doi.org/10.33330/jurteksi.v5i1.294

Available online at http://jurnal.stmikroyal.ac.id/index.php/jurteksi

dan dengan menggunakan persamaan.

V1:(0.6) $(0.5)+(0.8)(0.67)+(0.8)(1)+(1)(0,6$

$7)+(0.8)(0,33)+(0.4)(1)=3.802$

V2:(0.6) $(1)+(0.8)(1)+(0.8)(1)+(1)(1)+(0.8)$

$(1)+(0.4)(1)=4.4$

V3:(0.6) $(0.33)+(0.8)(1)+(0.8)(1)+(1)(1)+($

$0.8)(0.67)+(0.4)(0.33)=3.466$

V4:(0.6) $(0.33)+(0.8)(0.5)+(0.8)(0.67)+(1)($

$0.5)+(0.8)(0.33)+(0.4)(0.33)=2.03$

V5:(0.6) $(0.67)+(0.8)(0.25)+(0.8)(0.33)+(1$

)$(0.5)+(0.8)(0.33)+(0.4)(0.67)=1.898$

V6:(0.6) $(0.33)+(0.8)(1)+(0.8)(0.67)+(1)(0$.

$75)+(0.8)(0.67)+(0.4)(0.33)=2.952$

V7:(0.6) $(0.67)+(0.8)(0.25)+(0.8)(0.33)+(1$

)$(0.25)+(0.8)(0.67)+(0.4)(0.33)=1.784$

V8: $(0.6)(1)+(0.8)(1)+(0.8)(0.33)+(1)(1)+($

$0.8)(0.67)+(0.4)(1)=3.6$

V9:(0.6) $(0.67)+(0.8)(1)+(0.8)(0.67)+(1)(1)$

$+(0.8)(0.67)+(0.4)(0.67)=3.542$

Tabel Rangking

\begin{tabular}{lll}
\hline Alternatif & Nama & Nilai \\
\hline V2 & Sahren & 4.4 \\
\hline V1 & Fauzi Ahmad & 3.802 \\
\hline V8 & Junaidi & 3.6 \\
\hline V9 & Widra Widhana & 3.542 \\
\hline V3 & Ricky & 3.466 \\
\hline V6 & Ridwan & 2.952 \\
\hline V4 & Rudy Hermawan & 2.03 \\
\hline V5 & Riko & 1.898 \\
\hline V7 & Hendra Kurniawan & 1.784
\end{tabular}

\section{SIMPULAN}

Dari hasil penelitian tersebut maka diperoleh kesimpulan yaitu :

1. Sistem yang dibuat dengan model Fuzzy MADM (Multiple Attribute Decision Making) dengan metode SAW (Simple additive weight) dapat memberikan alternatif dan mempercepat hasil perhitungan penerimaan Karyawan baru khususnya asisten laboraturium.

2. Perhitungan Fuzzy MADM ini diterapkan berdasarkan kriteria-kriteria dan bobot yang telah ditentukan, dimana perhitungannya dengan melakukan normalisasi matrik semua kriteria. Hasil akhir dari penelitian ini adalah sebuah alternatif yang memiliki nilai terbaik yang dapat mempercepat hasil perangkingan dalam penentuan proses penerimaan Karyawan baru di STMIK Royal.

3. Sistem pendukung keputusan ini nantinya dapat mambantu pihak SDM dalam menentukan perekrutan karyawan baru khususnya asisten laboraturium di STMIK ROYAL.

\section{DAFTAR PUSTAKA}

[1] Alif Wahyu Okta Putra, 2014, Sistem Pendukung Keputusan Kelayakan Pemberian Kredit Motor Menggunakan metode Simple Additive Weighting pada Pada Perusahaan Leasing HD Finance.

[2] Turban, E, 2005, Decision Support Systems and Intelligent Systems Edisi Bahasa Indonesia Jilid 1, Andi, Yogyakarta.

[3] Dwi Citra Hartini, et al (2013). Sistem Pendukung Keputusan Pemilihan Hotel Di Kota Palembang Dengan Metode Simple Additive Weighting (SAW).

[4] Melisa Elistri, et al (2014). Penerapan Metode Saw Dalam Sistem Pendukung Keputusan Pemilihan Jurusan Pada Sekolah Menengah Atas Negeri 8 SelumaThomas L.Saaty. (1999). Fundamental Of The Analytic Network Process. 